\title{
Management of Obesity-Induced Kidney Disease: A Critical Review of the Literature
}

\author{
Dimitrios N. Kiortsis Maria A. Christou \\ Laboratory of Physiology, Medical School, University of Ioannina, Greece
}

\author{
Key Words \\ Obesity $\cdot$ Kidney disease $\cdot$ Weight loss $\cdot$ Albuminuria $\cdot$ Creatinine
}

\begin{abstract}
It is well established that obesity is a risk factor for the development of chronic kidney disease (CKD) and may promote the progression to end stage renal disease (ESRD). Therefore, it is strongly suggested that reduction of body weight can be an important intervention in order to reduce the prevalence of renal impairment. The current article describes extensively the already published trials which have studied the association between weight loss and kidney disease. The weight management programs include surgical and non-surgical interventions (low-calorie diet, aerobic exercise, drug-induced weight loss, combination treatment). The focus has been placed on the following renal function markers: albuminuria, proteinuria, glomerular filtration rate (GFR), and creatinine clearance. This review also aims to clarify challenges that clinicians have to deal with in everyday practice regarding the management of obesity-induced kidney disease (degree of weight loss, duration of the weight loss program, early initiation of the intervention).

Copyright (C) 2012 S. Karger GmbH, Freiburg
\end{abstract}

\section{Introduction}

Over the last decades, the prevalence of obesity has reached epidemic proportions in developed and developing countries worldwide. Regarding recent data from the National Health and Nutrition Examination Survey (NHANES), $32.2 \%$ of the US adults were obese with a BMI $\geq 30 \mathrm{~kg} / \mathrm{m}^{2}$ [1]. Obesity-related comorbidities, mainly type 2 diabetes, cardiovascular disease, dyslipidemia and hypertension, are well documented. An equally important but less investigated complication of obesity is chronic kidney disease (CKD), defined as 
Table 1. Stages of CKD

\begin{tabular}{lll}
\hline Stage & Description & GFR $\left(\mathrm{ml} / \mathrm{min} / 1.73 \mathrm{~m}^{2}\right)$ \\
\hline 1 & kidney damage with normal or $\uparrow \mathrm{GFR}$ & $\geq 90$ \\
2 & kidney damage with mild $\downarrow$ GFR & $60-89$ \\
3 & moderately $\downarrow$ GFR & $30-59$ \\
4 & severely $\downarrow$ GFR & $15-29$ \\
5 & kidney failure & $<15$ (or dialysis) \\
\hline
\end{tabular}

either kidney damage (abnormalities in blood or urine tests or imaging studies) or decreased kidney function (glomerular filtration rate (GFR) $<60 \mathrm{ml} / \mathrm{min} / 1.73 \mathrm{~m}^{2}$ ) for 3 or more months. Table 1 shows the classification of stages of CKD [2]. Interestingly, the prevalence of CKD (stages 1-4) has risen over the last years from 10 to 13\% [3]. Moreover, a metaanalysis estimated that $24.2 \%$ and $33.9 \%$ of CKD cases among US men and women, respectively, could be related to obesity [4]. CKD is associated with premature mortality, decreased quality of life, and increased healthcare expenditures. This article reviews thoroughly the studies concerning the management of obesity-induced kidney disease. It also attempts to elucidate any confusion on this matter, specifically regarding the amount of weight loss which has to be achieved, the duration of the follow-up period in the weight management programs, and the identification of those patients who will benefit most from weight loss. The literature search was based on PubMed listings up to January 11, 2012.

\section{Obesity and Kidney Disease}

A number of studies suggests that obesity per se, independent of its association with hypertension and/or diabetes, can play an important role in the development of CKD. Obesity can also promote the progression of underlying renal disease, even causing end stage renal disease (ESRD). Indeed, the Framingham Offspring Study in 2,585 individuals with nearly 19 years of follow-up reported that BMI increased the odds of developing kidney disease by $23 \%$ per standard deviation unit [5]. The Hypertension Detection and Follow-up Program found that, compared with normal-weight patients (BMI $18.5-24.9 \mathrm{~kg} / \mathrm{m}^{2}$ ), the risk of developing CKD at 5 years was $20 \%$ and $40 \%$ for overweight and obese subjects, respectively [6]. Additionally, in a large cohort of 320,252 patients who were followed up for 26 years, it was found that a high BMI was a strong risk factor for ESRD, even after adjustment for baseline blood pressure and diabetes status [7]. The risk for ESRD increased steadily from a lower to a higher BMI with odds ratios (OR) of 3.11 and 4.39 for overweight and obese patients, respectively.

\section{Pathogenesis of Obesity-Induced Kidney Disease}

Adipose tissue produces and releases a number of bioactive substances such as adipokines, pro-inflammatory mediators, and components of the renin-angiotensin-aldosterone system (RAAS). Leptin, whose levels are increased in obesity, can stimulate proliferation of endothelial cells, hypertrophy of mesangial cells, vascular inflammation, and oxidative stress. It can also increase the production of transforming growth factor(TGF)- $\beta_{1}$ and collagen type I and type IV which in turn can induce renal fibrosis. Animal studies show that infusion of leptin into normal rats results in the development of glomerulosclerosis and 
proteinuria [8]. Another proposed mechanism involves adiponectin which is decreased in obesity. Adiponectin knockout mice have profound proteinuria and foot process effacement that both improve with exogenous adiponectin treatment [9]. Interestingly, low adiponectin levels have been related with renal dysfunction and proteinuria $[10,11]$. The pro-inflammatory cytokine TNF- $\alpha$ constitutes another causal factor of obesity-induced CKD. Binding of TNF- $\alpha$ to its receptors, particularly TNF- $\alpha$ type 1 receptors,results in macrophage infiltration, apoptosis, and up-regulation of NF- $\kappa \mathrm{B}$ and TGF- $\beta 1$. These molecules may be toxic to renal epithelial, mesangial, and endothelial cells [12]. Additionally, IL- 6 activates the local RAAS system [13] and also enhances TGF- $\beta 1$ signaling and therefore renal fibrosis [14]. IL-6 probably controls high-sensitivity C-reactive protein (hs-CRP) production by the liver, which is associated with high risk of impaired glomerular filtration [15]. It is also possible that adipocytes themselves contribute to the increase in plasma hs-CRP levels [16]. Moreover, an increased renal sodium reabsorption has been observed in obesity, and this impaired natriuresis is likely to play an important role in the vasodilation of afferent glomerular arteriole and the consequent transmission of increased arterial pressure to the glomerular capillary. Increased renal sympathetic activity and activation of the RAAS system are other important stimuli for obesity-related increased renal sodium reabsorption [17].

\section{Obesity-Associated Renal Effects}

The renal effects of obesity can be divided into two categories: structural and functional [18]. The structural changes include the obesity-related glomerulopathy (ORG), which is characterized by focal segmental glomerulosclerosis (FSGS), glomerulomegaly, mesangial hyperplasia and minimal foot process fusion, with FSGS and glomerulomegaly being most often encountered [19]. The functional changes initially include progressive increase in GFR and increased renal blood flow. This likely occurs because of afferent arteriolar dilation as a result of proximal salt reabsorption, coupled with efferent renal arteriolar vasoconstriction as a result of elevated angiotensin II. These effects may contribute to a process called glomerular hyperfiltration [17]. The increase of GFR is followed by increased urinary albumin excretion (UAE), which may reach the magnitude of being defined as microalbuminuria (30-300 mg/day). At this stage (stage 1), the functional changes are potentially reversible with no or minimal histological lesions. This phase is followed by progressive fall in GFR and worsening histology lesions (stage 2). Without treatment, the functional and structural changes may progress, in parallel with a further rise in UAE ( $>300 \mathrm{mg} /$ day) and hyperfiltration of larger plasma macromolecules. Diffuse glomerusclerosis and tubulointerstitial fibrosis become apparent [20,21]. It should be underlined that GFR is increased at the initial stages of kidney disease, and therefore the various interventions aim to decrease it. In contrast, at the advanced stages GFR is decreased, and the interventions would be beneficial if an increase of GFR occurs.

\section{Weight Loss and Kidney Disease}

\section{Non-Surgical Interventions}

\section{Dietary Treatment}

In a small study, 22 obese patients with diabetic nephropathy treated with a low-calorie normal-protein diet were followed up for 4 weeks [22]. It was found that body weight decreased by $6.2 \pm 3 \mathrm{~kg}$, along with a significant decrease in visceral and subcutaneous fat. 
There was also a significant decrease in serum creatinine, blood urea nitrogen, and urinary protein (mean decrease $1.8 \pm 1.7 \mathrm{~g} /$ day). There was a trend towards increase regarding creatinine clearance, but this change was not statistically significant (baseline level $40.8 \pm$ $17.4 \mathrm{ml} / \mathrm{min}$ ). Interestingly, the study reported that change in body weight and visceral fat (but not subcutaneous fat) were significantly correlated with change in serum creatinine and urinary protein. Another study randomized 30 overweight/obese patients (BMI $>27$ $\mathrm{kg} / \mathrm{m}^{2}$ ) with diabetic and non-diabetic nephropathies to either follow a low-calorie normoproteinic diet or maintain their usual diet for 5 months [23]. Mean weight loss in the diet group was $4.1 \pm 3 \%$, whereas patients in the control group showed a significant increase in body weight. Proteinuria decreased by $31.2 \pm 37 \%$ in the diet group (from $2.8 \pm 1.4$ $\mathrm{g} /$ day to $1.9 \pm 1.4 \mathrm{~g} / \mathrm{day}$ ), whereas it tended to increase in the control group. Changes in renal function (serum creatinine, creatinine clearance) did not differ significantly between groups, although renal function remained stable in the diet group and showed significant worsening in the control group. It can be concluded that a moderate weight loss can induce a significant decrease in proteinuria and may also decrease the rate of progression of renal disease. A small study examined 24 type 1 and type 2 diabetic patients with obesity and overt nephropathy (albuminuria $>300 \mathrm{mg} /$ day) for 12 months after hypocaloric change from 1,870 to $1,410 \mathrm{kcal} /$ day [24]. At the end of the follow-up period the authors found a significant reduction of body weight (BMI decreased from $33 \pm 1.6$ to $26 \pm 1.8 \mathrm{~kg} / \mathrm{m}^{2}$ ), concomitantly with a marked decrease of proteinuria (from 1,280 \pm 511 to $623 \pm 307$ $\mathrm{mg} / \mathrm{day}$ ) and albuminuria (from $723 \pm 388$ to $492 \pm 170 \mu \mathrm{g} / \mathrm{min}$ ) and an improvement of GFR (from $66 \pm 13$ to $81 \pm 11 \mathrm{ml} / \mathrm{min} / 1.73 \mathrm{~m}^{2}$ ) and creatinine clearance (from $79 \pm 14$ to $91 \pm 13 \mathrm{ml} / \mathrm{min}$ ). Therefore, body weight reduction by hypocaloric diet may delay the progression of overt nephropathy in obese diabetic patients. 25 patients with BMI $\geq 25$ $\mathrm{kg} / \mathrm{m}^{2}$ were prescribed a low-calorie diet for 12 months [25]. At the end of the study the subjects were classified into two groups. Group A consisted of 10 patients who had a weight loss of at least $5 \%$, and group B consisted of 15 patients who did not experience weight loss. It was found that urinary sodium excretion and UAE rate were significantly decreased in group A, whereas these changes were not observed in group B. Importantly, UAE rate correlated significantly with weight reduction. Praga et al. [26] examined 17 obese patients with proteinuria $>1 \mathrm{~g}$ /day for 12 months. Nine patients followed a hypocaloric diet (baseline proteinuria $2.9 \pm 1.7 \mathrm{~g} /$ day), whereas 8 patients were treated with captopril (angiotensinconverting enzyme inhibitor (ACEI)) without dietary changes (baseline proteinuria $3.4 \pm$ $1.7 \mathrm{~g} /$ day). Both the hypocaloric diet and the captopril treatment induced a significant reduction in proteinuria after 6 months (mean decrease 1.7 and $2.2 \mathrm{~g} /$ day, respectively) and 12 months (mean decrease 2.5 and $2.7 \mathrm{~g} /$ day, respectively) of follow-up. From the abovementioned studies it is clear that low-calorie diet is associated with a decrease in albuminuria and/or proteinuria. Despite the limited data concerning GFR and/or creatinine clearance, there is a trend towards improvement of these parameters, especially when the degree of weight loss is significant [24].

\section{Exercise}

Only 1 study assessed the effects of physical activity on renal parameters [27]. 30 male type 2 diabetic patients with a mean BMI of $30.8 \pm 3 \mathrm{~kg} / \mathrm{m}^{2}$ at baseline were studied for 6 months. Microalbuminuria was found in 6 patients (20\%) at baseline, in 3 patients $(10 \%)$ after 3 months, and only in 1 patient (3.33\%) at the end of the study period. No changes in urinary enzyme activity typical of tubular damage were found. The authors concluded that a 6-month aerobic exercise in type 2 diabetic patients tended to decrease microalbuminuria without changing enzymuria. 


\section{Pharmacotherapy}

Only 1 study examined the effects of a weight loss drug on kidney function [28]. 33 obese patients with diabetes and 27 obese non-diabetic patients were administered orlistat $120 \mathrm{mg} 3$ times daily, without a concomitant hypocaloric diet for 6 months. The non-diabetic subjects, compared with the diabetic patients, had greater reduction of weight (4.8 vs. $3.1 \%$ ) and waist circumference (WC) (5.1 vs. 3.6\%) and also greater improvement of albuminuria (21.1 vs. 18.2\%), despite the fact that at baseline the diabetic patients had higher UAE levels $(17.1 \pm 3.8$ vs. $84.6 \pm 6.9 \mathrm{mg} /$ day, $)$.

\section{Combination Treatment}

A study evaluated the effects of a weight management program comprising low-fat diet, exercise, and orlistat on 32 obese patients with CKD [29]. 22 obese subjects with CKD formed the control group and received standard care. It was found that this combined approach decreased body weight (6.9\%) and waist circumference (11.4\%), whereas GFR continued to decrease (from $44.8 \pm 26$ to $35.5 \pm 19.6 \mathrm{ml} / \mathrm{min}$ ). Another study evaluated the effects of an intervention comprising low-calorie diet, exercise, and metformin in healthy overweight/ obese normoalbuminuric adults [30]. Group I consisted of 23 subjects who had UAE $<10$ $\mathrm{mg} /$ day and creatinine clearance $108 \pm 9 \mathrm{ml} / \mathrm{min}$, whereas group II consisted of 18 subjects with UAE of 10-29 mg/day and creatinine clearance of $148 \pm 14 \mathrm{ml} / \mathrm{min}$. Although the intervention induced comparable reductions in body weight, UAE was significantly reduced in group II (mean decrease $9.1 \pm 1.8 \mathrm{mg} /$ day) and non-significantly in group I. Additionally, greater improvement in creatinine clearance was observed in subjects of group II. It is known that topiramate has been approved for the treatment of seizure disorders and for migraine prophylaxis. Moreover, topiramate can induce significant weight loss [31]. Therefore, a study in obese subjects with type 2 diabetes examined the efficacy of topiramate as an adjunct to diet and exercise [32]. The patients were randomized to placebo, topiramate $96 \mathrm{mg} /$ day or topiramate $192 \mathrm{mg} /$ day. All individuals followed a weight loss program which consisted of a diabetic diet, a behavioral modification program, and a physical activity program. The placebo, the topiramate $96 \mathrm{mg} /$ day and the topiramate $192 \mathrm{mg} /$ day groups lost 2.5, 6.6 and $9.1 \%$ of their baseline body weight, respectively. The baseline levels and the mean decrease of urinary albumin in the three groups were $27.17,31.69$ or $28.43 \mathrm{mg} /$ day and $1.01,16.19$ or $15.72 \mathrm{mg} /$ day, respectively. Therefore, the two former studies have shown that baseline UAE $<30 \mathrm{mg}$ /day, just below the conventionally used level to define microalbuminuria, is sensitive to interventions that produce weight loss. It can be concluded that the combined weight management programs can induce a significant decrease in albuminuria, whereas the data regarding GFR and creatinine clearance are limited and inconsistent. It can be also said that the baseline kidney function probably plays a major role.

\section{Surgical Interventions}

A number of studies have shown that surgical weight loss is associated with reduction in serum creatinine, albuminuria and proteinuria, and also with an improvement of GFR [33-37]. In a study, 70 extremely obese adults were prospectively studied before and 12 months after bariatric surgery and were compared with 24 normal-weight adults [38]. It was found that after surgery the drastic decreases in BMI and waist circumference were associated with improvements in adipokines (leptin, adiponectin), pro-inflammatory parameters (hs-CRP, fibrinogen), and renal parameters (creatinine clearance (from 125 $(110-170)$ to $112(89-143) \mathrm{ml} / \mathrm{min})$, proteinuria (from $0.14(0.09-0.32)$ to $0.11(0.08-0.14)$ $\mathrm{g} /$ day), and albuminuria (from 14.8 (8-61) to 12.8 (9.2-24.6) mg/day)). Moreover, 12 months 
after surgery, creatinine clearance and proteinuria did not differ significantly compared with the control group, whereas leptin, pro-inflammatory parameters, and albuminuria remained significantly higher when compared with the controls. Notably, adiponectin not only increased after surgery but exceeded the levels of the control subjects. Navaneethan et al. [39] determined the effects of weight loss induced by different types of bariatric surgery on adipokines and albuminuria in 15 severely obese type 2 diabetic patients followed up for 6 months. In all patients who underwent bariatric surgery, there was a significant decrease in BMI and leptin levels, along with a significant increase in high molecular weight (HMW) adiponectin levels. Notably, there was a marked reduction in serum creatinine after surgery and also a non-significant decrease in urine albumin/creatinine ratio (ACR) for the entire group. In patients who underwent Roux-en-Y gastric bypass (RYGB), there was a significant decrease in BMI, leptin, serum creatinine, and ACR (from 36 (7-94) to 27 (5.5-42.5) mg/g), along with a significant increase in HMW adiponectin. The reduction in ACR was inversely correlated with HMW adiponectin. In patients who underwent other types of bariatric surgery, there was similar reduction in BMI compared with the RYGB patients and also significant decreases in serum creatinine and leptin. However, the changes in ACR and HMW adiponectin were non-significant.

A retrospective study examined 62 obese adults who had undergone RYGB with a median follow-up of 15 months [40]. It was shown that CRP and albuminuria decreased with weight loss after bariatric surgery. The study sample was then divided into tertiles based on the percentage of weight loss. Interestingly, the trend toward a greater reduction in these parameters with increased weight loss was found to be non-significant for albuminuria, but significant for CRP. The authors suggested that the absence of a significant graded relation between weight loss and albuminuria reduction was due to the fact that adipose tissue in obesity might not have a direct effect on albuminuria but an indirect effect through multiple metabolic pathways. In another study, 61 extremely obese patients were studied prospectively before and 24 months after bariatric surgery [41]. Control subjects were 24 normalweight adults. The authors found that there was a significant improvement in creatinine clearance (from $139.51 \pm 41.90$ to $119.59 \pm 44.24 \mathrm{ml} / \mathrm{min}$ ), proteinuria (from 0.14 (0.090.32 ) to $0.11(0.08-0.14) \mathrm{g} /$ day), albuminuria (from 14.20 (7.95-92.2) to 13 (9.25-25.25) $\mathrm{mg} /$ day), and microhematuria at 12 months of follow-up. This improvement occurred mainly in the first year after surgery, because this is when the majority of weight loss takes place. Interestingly, albuminuria continued to decrease during the 2nd year of follow-up, whereas the improvement of the other parameters was non-significant. A retrospective study was performed in obese adults who underwent RYGB [42]. Of the 94 obese patients, 32 had type 2 diabetes and 37 had metabolic syndrome. After the 12-month follow-up, there was a significant decrease in urine ACR (from 9.5 (5-28) to 5.5 (3-10) mg/g). Subgroup analysis revealed that the decrease in ACR was significant in the 32 patients with diabetes (from 16.5 (5-67) to $6(4-11) \mathrm{mg} / \mathrm{g}$ ) and in the 37 patients with metabolic syndrome (from 8 (5-16) to 6 (3-13) $\mathrm{mg} / \mathrm{g}$ ). Therefore, this study shows that obese subjects can achieve a decrease in albuminuria after surgical weight loss, particularly in those patients suffering from diabetes or metabolic syndrome. During a 12-month follow-up period, Saliba et al. [43] studied the changes in glomerular and tubular function that occurred after RYGB in 19 diabetic and 16 non-diabetic subjects with morbid obesity. Glomerular function was estimated using creatinine clearance, whereas tubular function was studied by measuring the UCC ratio (urinary cystatin $\mathrm{C}$ to urinary creatinine). In non-diabetic subjects the renal defects, primarily glomerular, normalized with RYGB (21\% decrease in creatinine clearance). In contrast, in diabetic individuals the renal defects were both glomerular and tubular. RYGB improved but did not normalize the glomerular defects (15\% decrease in creatinine clearance), while the tubular defects continued to worsen (significant increase of the UCC ratio at both 6 and 12 
Table 2. Effects of weight loss interventions on renal function parameters

\begin{tabular}{|c|c|c|c|}
\hline Type of intervention & $\begin{array}{l}\text { Impact on GFR and/or } \\
\text { creatinine clearance }\end{array}$ & $\begin{array}{l}\text { Impact on albuminuria } \\
\text { and/or proteinuria }\end{array}$ & Comments \\
\hline $\begin{array}{l}\text { Diet } \\
\text { (5 studies) }\end{array}$ & $\begin{array}{l}+(1 \text { study }) \\
\leftrightarrow(2 \text { studies })\end{array}$ & $\downarrow$ (5 studies) & $\begin{array}{l}\text { trend towards improvement } \\
\text { of GFR and creatinine } \\
\text { clearance, especially when } \\
\text { the degree of weight loss is } \\
\text { significant }\end{array}$ \\
\hline $\begin{array}{l}\text { Exercise } \\
\text { (1 study) }\end{array}$ & NA & $\downarrow$ & - \\
\hline $\begin{array}{l}\text { Pharmacotherapy } \\
\text { (1 study) }\end{array}$ & NA & $\downarrow$ & $\begin{array}{l}\text { orlistat may be more } \\
\text { effective to decrease } \\
\text { albuminuria in non-diabetics } \\
\text { than diabetics }\end{array}$ \\
\hline $\begin{array}{l}\text { Combination treatment } \\
\text { (3 studies) }\end{array}$ & $\begin{array}{l}+(1 \text { study }) \\
-(1 \text { study })\end{array}$ & $\downarrow$ (2 studies) & $\begin{array}{l}\text { not well established data } \\
\text { about GFR and creatinine } \\
\text { clearance, the baseline } \\
\text { kidney function probably } \\
\text { plays a major role }\end{array}$ \\
\hline $\begin{array}{l}\text { Bariatric surgery } \\
\text { (10 studies) }\end{array}$ & $+(5$ studies $)$ & $\downarrow$ (8 studies) & $\begin{array}{l}\text { significant improvement of } \\
\text { renal function in all studies }\end{array}$ \\
\hline
\end{tabular}

$\leftrightarrow=$ No change; + = improvement; - = worsening; $\downarrow$ = decrease; NA = not assessed.

months). Importantly, the improvement in creatinine clearance, though seen in both groups, occurred within 6 months in the non-diabetics and normalized after 12 months, whereas it did not occur until 12 months after RYGB in the diabetics and still remained higher than the normal levels. Therefore, from the studies described above it can be concluded that bariatric surgery is effective not only to decrease albuminuria and proteinuria but also to improve GFR and creatinine clearance.

Despite the afore-mentioned studies which refer to individuals without significant renal impairment at baseline, Alexander et al. [44] examined 45 morbidly obese patients with established renal disease who had undergone gastric bypass. Of the 45 patients, 22 were already receiving dialysis. The authors reported that 9 patients had stabilization, improvement, or resolution of their kidney disease. Of these 9 patients, 5 had a primary diagnosis of focal segmental glomerulosclerosis, 2 had membranous glomerulonephritis, and 2 had diabetic nephropathy. It is remarkable that 2 patients could discontinue dialysis for 27 or 7 months. The same author had previously reported an initial experience with gastric bypass in morbidly obese patients with chronic renal failure [45]. This study elucidated that of the 41 patients (25 already receiving dialysis), 5 stabilized or resolved their kidney disease.

\section{Discussion}

All those studies which assessed the management of obesity-induced kidney disease show a significant decrease in albuminuria and proteinuria. Regarding improvement of GFR and creatinine clearance, bariatric surgery seems to be the most effective weightmanagement approach (table 2). However, the results of the various studies should be interpreted with 
caution and direct comparison of the surgical and non-surgical studies should be avoided for several reasons (i.e., different baseline anthropometric and/or kidney function characteristics, different follow-up periods). A major issue regarding the currently studied topic is the amount of weight loss which has to be achieved in order to improve renal impairment. It has to be noted that most of the studies did not establish a clear association between the amount of weight loss and the improvement of renal parameters. A study found that the changes of serum creatinine and urinary protein correlated significantly with the decrease in body weight and visceral fat [22]. However, this study has a relatively small sample size (22 patients) and also a short follow-up period (4 weeks). Moreover, in another study it was shown that there was a significant correlation between weight loss and decrease in albuminuria [25]. The same study also reported that the UAE rate was significantly decreased in those individuals who had a weight loss of at least $5 \%$. Similarly, it was found that the reduction in body weight correlated significantly with the decrease in proteinuria [32]. Interestingly, bariatric surgery (especially the RYGB procedure) can achieve significant weight loss, along with great improvement in renal parameters. Therefore, it appears that the greater the weight loss, the more pronounced the improvement of renal disease. However, clinicians should emphasize the benefits of an even modest weight loss because it can induce a significant decrease in proteinuria $[22,23,32]$. A number of studies have documented that in patients requiring dialysis for CKD, particularly hemodialysis, obesity has a paradoxic neutral or even protective relationship with mortality [46-48]. These data confuse the clinicians regarding weight loss interventions in obese subjects receiving dialysis. The major limitation of these studies is the fact that the association between obesity and reduced mortality is based entirely on observational studies that cannot prove causality. No study has shown that weight gain lowers mortality or that intentional weight loss adversely affects patients' outcomes. Moreover, in all studies obesity was defined by BMI which does not reflect accurately body composition and fat distribution. Therefore, low mortality in dialysis patients with high BMI can be due to edema, increased muscle mass $[49,50]$, and/or peripheral fat distribution. Furthermore, most studies had a relatively short follow-up and only a small number of patients with BMI $\geq 35 \mathrm{~kg} / \mathrm{m}^{2}$.

Another aspect which should be taken into account is the duration of the follow-up period in the weight management programs. In many studies it was found that the decrease in albuminuria and serum creatinine and the improvement of GFR were greater at 12 months than 6 months of follow-up [32,36]. Similarly, in another study it was shown that the further decrease in albuminuria during the 2nd year of follow-up was disproportionally greater compared to the amount of body weight loss [41]. Therefore, there is probably a positive association between the duration of the follow-up period and the improvement of kidney disease. The initiation of the weight management programs should begin early in the course of CKD when the kidney lesions are not yet irreversible. Although in most studies weight loss resulted in an improvement of kidney function, in 1 study it was found that a combined intervention resulted in significant reduction of body weight and waist circumference, whereas GFR continued to worsen [28]. A possible explanation for this discrepancy is that most subjects in the latter study had moderate or advanced kidney disease (stage 2-4 CKD, dialysis patients). However, Alexander et al. $[44,45]$ reported stabilization, improvement, or resolution of advanced CKD in a number of patients who had undergone bariatric surgery. Consequently, further studies are needed in order to identify those patients who will benefit most from weight loss. It has been shown that waist circumference and waist-to-hip ratio (WHR) as indices of visceral obesity are probably more sensitive predictors of renal injury than BMI [51, 52]. Indeed, even lean individuals have a greater risk of developing microalbuminuria and reduced GFR when their WHR is high [51]. Additionally, the decrease in visceral, but not subcutaneous fat has been significantly associated with the reduction in 
serum creatinine and urinary protein levels [22]. Importantly, patients who lose weight might also lose muscle mass with a concomitant decrease in serum creatinine levels, creating the false impression that there is improvement of renal disease. Therefore, BMI should be combined with other anthropometric parameters in order to assess accurately body composition and fat distribution.

Many studies examining the association between weight loss and kidney disease had significant limitations, such as small sample size, short duration of follow-up, heterogeneity of the groups regarding sex, absence of control group, presence of control group with normalweight instead of obese subjects, assessment of renal parameters with different methods. Notably, only few studies assessed GFR and creatinine clearance, and many of them used the indirect estimating methods. These methods have many limitations, especially the fact that they have been derived from lean individuals and are therefore less accurate in obese subjects. Furthermore, in the Cockcroft-Gault equation (GFR $(\mathrm{ml} / \mathrm{min})=((140-$ age $) \mathrm{x}$ weight) $\times 0.85$ if female) $/ 72 \times$ serum creatine) the value of GFR is proportional to body weight. Therefore, the changes of body weight of a given person over time can result in relevant alterations of GFR which are attributed mainly to changes in renal hemodynamics. This phenomenon represents changes in renal function, and not structural renal abnormalities. During these body weight changes, although absolute GFR changes too, the GFR corrected for body weight remains the same. In this aspect, the GFR corrected for body surface should be taken into account.

Moreover, in many cases drugs with renal protective effects (ACEIs, angiotensin II receptor blockers (ARBs)) were not withdrawn, but they were continued during the study as part of the management of baseline hypertension and/or diabetic nephropathy. Pharmacological targeting of the RAAS system (ARBs, ACEIs) can be used as an adjunctive therapy because it reduces blood pressure and it also provides more direct renal protection. Indeed, after a decade of research there is a large body of evidence supporting improvement in renal outcomes with ARBs. Four ARBs, namely losartan, irbesartan, valsartan and telmisartan, have shown efficacy in slowing the onset of kidney disease and/or slowing progression of CKD. The reduction of proteinuria by ARBs is linked to improved cardiovascular outcomes, probably due to protective effects on the general vasculature [53]. We cannot exclude the existence of treatments that result in albuminuria reduction without improvement of GFR. However, the possible underlying mechanisms of these treatments are not clear yet [54].

The management of obesity should begin with an appropriate dietary intervention. There is a wide variety of healthy diets that can be considered in order to lose weight. Popular alternatives for short-term weight loss are the low-carbohydrate diets which restrict carbohydrate intake and increase fat and protein content. A frequently cited concern of low-carbohydrate diets is the potential for increased risk of renal disease associated with high protein intake $[55,56]$. However, several studies suggested that the consumption of a low-carbohydrate weight loss diet may not adversely affect renal function, at least in individuals without overt renal disease at baseline $[57,58]$. Bariatric surgery should be performed in morbidly obese individuals or in subjects with comorbidities. Importantly, surgical interventions can often cause rhabdomyolysis [59] and hyperoxaluria, with increased risk of renal stone formation [60] and even oxalate nephropathy [61]. Rhabdomyolysis and nephrolithiasis are major risk factors for the development of acute kidney injury, whereas oxalate nephropathy can lead to CKD and ESRD. The exact mechanisms underlying the benefits of weight loss regarding the treatment of obesity-induced CKD have not been elucidated yet. Specifically, it remains to be investigated whether the above mentioned benefits are due to the amount of weight loss per se or whether they are influenced by the dietary composition of the applied diet. 
It can be concluded that weight loss management programs are effective interventions in order to improve renal disease. Clinicians should assess each patient individually and should also emphasize the benefits of an overall healthy lifestyle. However, further studies should be carefully planned in order to clarify any conflicting data concerning the management of obesity-induced kidney disease.

\section{Disclosure Statement}

The authors have no conflict of interest.

\section{References}

1 Ogden CL, Carroll MD, Curtin LR, McDowell MA, Tabak CJ, Flegal KM: Prevalence of overweight and obesity in the United States, 1999-2004. JAMA 2006;295:1549-1555.

2 Levey AS, Coresh J, Balk E, Kausz AT, Levin A, Steffes MW, Hogg RJ, Perrone RD, Lau J, Eknoyan G; National Kidney Foundation: National Kidney Foundation Practice Guidelines for Chronic Kidney Disease: evaluation, classification and stratification. Ann Intern Med 2003;139:137-147.

3 Coresh J, Selvin E, Stevens LA, Manzi J, Kusek JW, Eggers P, Van Lente F, Levey AS: Prevalence of chronic kidney disease in the United States. JAMA 2007;298:2038-2047.

- 4 Wang Y, Chen X, Song Y, Caballero B, Cheskin LJ: Association between obesity and kidney disease: a systematic review and meta-analysis. Kidney Int 2008 Jan;73(1):19-33.

- 5 Fox CS, Larson MG, Leip EP, Culleton B, Wilson PW, Levy D: Predictors of new-onset kidney disease in a community-based population. JAMA 2004;291:844-850.

- 6 Kramer H, Luke A, Bidani A, Cao G, Cooper R, McGee D: Obesity and prevalent and incident CKD: the Hypertension Detection and Follow-up Program. Am J Kidney Dis 2005;46:587-594.

- 7 Hsu CY, McCulloch CE, Iribarren C, Darbinian J, Go AS: Body mass index and risk for end-stage renal disease. Ann Intern Med 2006;144:21-28.

8 Wolf G, Ziyadeh FN: Leptin and renal fibrosis. Contrib Nephrol 2006;151:175-183.

- 9 Sharma K, Ramachandrarao S, Qiu G, Usui HK, Zhu Y, Dunn SR, Ouedraogo R, Hough K, McCue P, Chan L, Falkner B, Goldstein BJ: Adiponectin regulates albuminuria and podocyte function in mice. J Clin Invest 2008;118:1645-1656.

$\checkmark 10$ Tsioufis C, Dimitriadis K, Chatzis D, Vasiliadou C, Tousoulis D, Papademetriou V, Toutouzas P, Stefanadis C, Kallikazaros I: Relation of microalbuminuria to adiponectin and augmented C-reactive protein levels in men with essential hypertension. Am J Cardiol 2005;96:946-951.

11 Lin J, Hu FB, Curhan G: Serum adiponectin and renal dysfunction in men with type 2 diabetes. Diabetes Care 2007;30:239-244.

12 Cunningham PN, Dyanov HM, Park P, Wang J, Newell KA, Quigg RJ: Acute renal failure in endotoxemia is caused by TNF acting directly on TNF receptor-1 in kidney. J Immunol 2002;168:5817-5823.

13 Wassmann S, Stumpf M, Strehlow K, Schmid A, Schieffer B, Böhm M, Nickenig G: Interleukin-6 induces oxidative stress and endothelial dysfunction by overexpression of the angiotensin II type 1 receptor. Circ Res 2004;94:534-541.

14 Zhang XL, Topley N, Ito T, Phillips A: Interleukin-6 regulation of transforming growth factor (TGF)-beta receptor compartmentalization and turnover enhances TGF-beta1 signaling. J Biol Chem 2005;280:1223912245.

$\longrightarrow 15$ Stuveling EM, Hillege HL, Bakker SJL, Gans ROB, de Jong PE, de Zeeuw D: C-reactive protein is associated with renal function abnormalities in a non-diabetic population. Kidney Int 2003;63:654-661.

16 Lau DC, Dhillon B, Yan H, Szmitko PE, Verma S: Adipokines: molecular links between obesity and atherosclerosis. Am J Physiol Heart Circ Physiol 2005;288:H2031-H2041.

17 Wahba IM, Mak RH: Obesity and obesity-initiated metabolic syndrome: mechanistic links to chronic kidney disease. Clin J Am Soc Nephrol 2007;2:550-562.

-18 Henegar JR, Bigler SA, Henegar LK, Tyagi SC, Hall JE: Functional and structural changes in the kidney in the early stages of obesity. J Am Soc Nephrol 2001;12:1211-1217.

19 Kambham N, Markowitz G, Valeri A, Lin J, D’Agati V: Obesity-related glomerulopathy: An emerging epidemic. Kidney Int 2001;59:1498-1509.

20 de Jong PE, Verhave JC, Pinto-Sietsma SJ, Hillege HL; PREVEND Study Group: Obesity and target organ damage: the kidney. Int J Obes Relat Metab Disord 2002;26:S21-S24.

21 Ruggenenti P, Remuzzi G: Time to abandon microalbuminuria? Kidney Int 2006;70:1214-1222. 
Kiortsis et al:: Management of Obesity-Induced Kidney Disease: A Critical Review of the Literature

22 Saiki A, Nagayama D, Ohhira M, Endoh K, Ohtsuka M, Koide N, Oyama T, Miyashita Y, Shirai K: Effect of weight loss using formula diet on renal function in obese patient with diabetic nephropathy. Int J Obes 2005;29:1115-1120.

23 Morales E, Valero MA, Leon M, Hernandez E, Praga M: Beneficial effects of weight loss in overweight patients with chronic proteinuric nephropathies. Am J Kidney Dis 2003;41:319-327.

$\checkmark 24$ Solerte SB, Fioravanti M, Schifino N, Ferrari E: Effects of diet-therapy on urinary protein excretion albuminuria and renal haemodynamic function in obese diabetic patients with overt nephropathy. Int J Obes 1989;13:203-211.

-25 Ohashi H, Oda H, Ohno M, Watanabe S: Weight reduction improves high blood pressure and microalbuminuria in hypertensive patients with obesity. Nihon Jinzo Gakkai Shi 2001;43:333-339.

26 Praga M, Hernandez E, Andres A, Leon M, Ruilope LM, Rodicio JL: Effects of body weight-loss and captopril treatment on proteinuria associated with obesity. Nephron 1995;70:35-41.

27 Lazarevic G, Antic S, Vlahovic P, Djordjevic V, Zvezdanovic L, Stefanovic V: Effects of aerobic exercise on microalbuminuria and enzymuria in type 2 diabetic patients. Ren Fail 2007;29:199-205.

28 Tong PC, Lee ZS, Sea MM, Chow CC, Ko GT, Chan WB, So WY, Ma RC, Ozaki R, Woo J, Cockram CS, Chan JC: The effect of orlistat-induced weight loss, without concomitant hypocaloric diet, on cardiovascular risk factors and insulin sensitivity in young obese Chinese subjects with or without type 2 diabetes. Arch Intern Med 2002;162:2428-2435.

-29 Cook S, MacLaughlin H, Macdougall IC: A structured weight management programme can achieve improved functional ability and significant weight loss in obese patients with chronic disease. Nephrol Dial Transplant 2008;23:263-268.

-30 Cubeddu LX, Alfieri AB, Hoffmann IS: Lowering the threshold for defining microalbuminuria: effects of a lifestyle-metformin intervention in obese normoalbuminuric non-diabetic patients. Am J Hypertens 2008; 21:105-110.

-31 Wilding J, Van Gaal L, Rissanen A, Vercruysse F, Fitchet M, for the OBES-002 Study Group: A randomized double-blind placebo-controlled study of the long-term efficacy and safety of topiramate in the treatment of obese subjects. Int J Obes 2004;28:1399-1410.

-32 Stenlof K, Rossner S, Vercruysse F, Kumar A, Fitchet M, Sjostrom L; OBDM-003 Study Group: Topiramate in the treatment of obese subjects with drug-naïve type 2 diabetes. Diabetes Obes Metab 2007;9:360-368.

-33 Chagnac A, Weinstein T, Herman M, Hirsh J, Gafter U, Ori Y: The effects of weight loss on renal function in patients with severe obesity. J Am Soc Nephrol 2003;14:1480-1486.

-34 Palomar R, Fernández-Fresnedo G, Domínguez-Diez A, López-Deogracias M, Olmedo F, Martín de Francisco AL, Sanz de Castro S, Casado Martín F, Gómez-Fleitas M, Arias M, Fernández-Escalante C: Effects of weight loss after biliopancreatic diversion on metabolism and cardiovascular profile. Obes Surg 2005;15:794798.

35 Serpa Neto A, Bianco Rossi FM, Dal Moro Amarante R, Alves Buriti N, Cunha Barbosa Saheb G, Rossi M: Effect of weight loss after Roux-en-Y gastric bypass, on renal function and blood pressure in morbidly obese patients. J Nephrol 2009;22:637-646.

-36 Navaneethan SD, Yehnert H: Bariatric surgery and progression of chronic kidney disease. Surg Obes Relat Dis 2009;5:662-665.

37 Schuster DP, Teodorescu M, Mikami D, Foreman K, Rogers P, Needleman BJ: Effect of bariatric surgery on normal and abnormal renal function. Surg Obes Relat Dis 2011;7:459-464

-38 Serra A, Granada ML, Romero R, Bayés B, Cantón A, Bonet J, Rull M, Alastrue A, Formiguera X: The effect of bariatric surgery on adipocytokines, renal parameters and other cardiovascular risk factors in severe and very severe obesity: 1-year follow-up. Clin Nutr 2006;25:400-408.

-39 Navaneethan SD, Kelly KR, Sabbagh F, Schauer PR, Kirwan JP, Kashyap SR: Urinary albumin excretion, HMW adiponectin and insulin sensitivity in type 2 diabetic patients undergoing bariatric surgery. Obes Surg 2010;20:308-315.

-40 Agrawal V, Krause KR, Chengelis DL, Zalesin KC, Rocher LL: Relation between degree of weight loss after bariatric surgery and reduction in albuminuria and C-reactive protein. Surg Obes Relat Dis 2009;5:20-26.

-41 Navarro-Díaz M, Serra A, Romero R, Bonet J, Bayés B, Homs M, Pérez N, Bonal J: Effect of drastic weight loss after bariatric surgery on renal parameters in extremely obese patients: long-term follow-up. J Am Soc Nephrol 2006;17:S213-S217.

42 Agrawal V, Khan I, Rai B, Krause KR, Chengelis DL, Zalesin KC, Rocher LL, McCullough PA: The effect of weight loss after bariatric surgery on albuminuria. Clin Nephrol 2008;70:194-202.

43 Saliba J, Kasim NR, Tamboli RA, Isbell JM, Marks P, Feurer ID, Ikizler A, Abumrad NN: Roux-en-Y bypass reverses renal glomerular but not tubular abnormalities in excessively obese diabetics. Surgery 2010;147: 282-291.

44 Alexander JW, Goodman HR, Hawver LM, Cardi MA: Improvement and stabilization of chronic kidney disease after gastric bypass. Surg Obes Relat Dis 2009;5:237-241.

45 Alexander JW, Goodman H: Gastric bypass in chronic renal failure and renal transplant. Nutr Clin Pract 2007;22:16-21.

46 Fleischmann E, Teal N, Dudley J, May W, BowerJD, Salahudeen AK: Influence of excessive weight on mortality and hospital stay in 1346 hemodialysis patients. Kidney Int 1999;55:1560-1567. 
-47 Leavey SF, McCullough K, Hecking E, Goodkin D, Port FK, Young EW: Body mass index and mortality in healthier as compared with sicker haemodialysis patients: results from the Dialysis Outcomes and Practise Patterns Study (DOPPS). Nephrol Dial Transplant 2001;16:2386-2394.

$\checkmark 48$ Johansen KL, Young B, Kaysen GA, Chertow GM: Association of body size with outcomes among patients beginning dialysis. Am J Clin Nutr 2004;80:324-332.

-49 Beddhu S, Pappas LM, Ramkumar N, Samore MH: Effects of body size and body composition on survival in hemodialysis patients. J Am Soc Nephrol 2003;14:2366-2372.

50 Araújo IC, Kamimura MA, Draibe SA, Canziani ME, Manfredi SR, Avesani CM, Sesso R, Cuppari L: Nutritional parameters and mortality in incident hemodialysis patients: Effect of body mass index, muscle mass and dietary intake. J Renal Nutr 2006;16:27-35.

51 Pinto-Sietsma SJ, Navis G, Janssen WM, de Zeeuw D, Gans RO, de Jong PE: A central body fat distribution is related to renal function impairment, even in lean subjects. Am J Kidney Dis 2003;41:733-741.

-52 Elsayed EF, Sarnak MJ, Tighiouart H, Griffith JL, Kurth T, Salem DN, Levey AS, Weiner DE: Waist-to-hip ratio, body mass index and subsequent kidney disease and death. Am J Kidney Dis 2008;52:29-38.

53 Schmieder RE, Ruilope LM, Barnett AH: Renal protection with angiotensin receptor blockers: where do we stand. J Nephrol 2011;24:569-580.

54 Navaneethan SD, Yehnert H, Moustarah F, Schreiber MJ, Schauer PR, Beddhu S: Weight loss interventions in chronic kidney disease: a systematic review and meta-analysis. Clin J Am Soc Nephrol 2009;4:15651574.

55 Friedman AN: High-protein diets: Potential effects on the kidney in renal health and disease. Am J Kidney Dis 2004;44:950-962.

$\$ 56$ Uribarri J, Tuttle KR: Advanced glycation end products and nephrotoxicity of high-protein diets. Clin J Am Soc Nephrol 2006;1:1293-1299.

-57 Yancy WS, Olsen MK, Guyton JR, Bakst RP, Westman EC: A low-carbohydrate, ketogenic diet versus a low-fat diet to treat obesity and hyperlipidemia: a randomized, controlled trial. Ann Intern Med 2004;140:769777.

58 Brinkworth GD, Buckley JD, Noakes M, Clifton PM: Renal function following long-term weight loss in individuals with abdominal obesity on a very-low-carbohydrate diet vs high-carbohydrate diet. J Am Diet Assoc 2010;110:633-638.

59 de Oliveira LD, Diniz MT, de Fatima H S Diniz M, Savassi-Rocha AL, Camargos ST, Cardoso F: Rhabdomyolysis after bariatric surgery by Roux-en-Y gastric bypass: a prospective study. Obes Surg 2009;19:11021107.

60 Sinha MK, Collazo-Clavell ML, Rule A, Milliner DS, Nelson W, Sarr MG, Kumar R, Lieske JC: Hyperoxaluric nephrolithiasis is a complication of Roux-en-Y gastric bypass surgery. Kidney Int 2007;72:100-107.

61 Nelson WK, Houghton SG, Milliner DS, Lieske JC, Sarr MG: Enteric hyperoxaluria, nephrolithiasis and oxalate nephropathy: potentially serious and unappreciated complications of Roux-en-Y gastric bypass. Surg Obes Relat Dis 2005;1:481-485. 